\title{
Response of Liver Tyrosine-catabolizing Enzymes in Rats Fed High Tyrosine Diets
}

\author{
Yukiko Yamamoto, Ryogo Toyoshima and Keiichiro Muramatsu \\ Laboratory of Food and Nutrition, Department of Agricultural Chemistry, Faculty of \\ Agriculture, Shizuoka University, Shizuoka, Japan
}

Received September 26, 1978

\begin{abstract}
Weanling rats were fed a $10 \%$ casein containing $5 \%$ tyrosine $(10 \mathrm{C} 5 \mathrm{~T})$ diet supplemented either with $20 \%$ casein or with $0.66 \%$ methionine plus $0.90 \%$ threonine for 7 days ad libitum, and then the activities of liver tyrosine-catabolizing enzymes: tyrosine (Tyr) transaminase; $p$-hydroxyphenylpyruvate (pHPP) hydroxylase; and homogentisate oxidase; were determined sequentially at various times during 24 -hr period. The mean activity of Tyr transaminase was elevated by feeding high tyrosine diets, except the methionine and threonine supplemented diet. The mean activity of pHPP hydroxylase was depressed by high tyrosine but was reversed by the addition of extra casein or methionine and threonine, and the ratio of Tyr transaminase and pHPP hydroxylase activities in rats consuming the 10C5T diet was remarkably elevated. The mean activity of homogentisate oxidase was somewhat depressed in rats fed the 10C5T diet, but was not affected by the additional casein or methionine and threonine supplements. In all dietary groups, Tyr transaminase showed a daily variation which included a maximal peak during darkness, whereas pHPP hydroxylase and homogentisate oxidase activities did not show so much clear daily variation. The high concentration of free tyrosine in body was markedly decreased by the addition of casein or methionine and threonine. It is suggested that the beneficial effect of extra casein or methionine and threonine supplementation on tyrosine toxicity may be due to the improvement of nutritional quality and the increase of the capacity of tyrosine metabolism by the increasing liver pHPP hydroxylase.
\end{abstract}

Supplemental effects of dietary protein ${ }^{1 \sim 5)}$ or some amino $\operatorname{acids}^{6 \sim 13)}$ on tyrosine toxicity which is observed in young rats fed a low protein-high tyrosine diet have been extensively studied. Our previous reports indicated that the addition of both methionine and threonine as well as extra protein completely prevents the tyrosine toxicity, ${ }^{11,12)}$ increasing the rate of tyrosine catabolism which resulted in lower tyrosine concentrations in body fluids. ${ }^{14)}$

Studies on liver tyrosine-catabolizing enzymes are important in understanding how tyrosine metabolism is stimulated by dietary addition of extra casein or methionine plus threonine. It has been well documented that liver Tyr transaminase in rats is induced by tyrosine, ${ }^{4,5,12,13,15,16)}$ dietary protein ${ }^{4,5,17 \sim 21)}$ and glucocorticoids and glucagon., ${ }^{4,19,21 \sim 23)}$ Increasing of dietary protein also causes an elevation of activities in both pHPP hydroxylase $e^{4,5)}$ and homogentisate oxidase. ${ }^{5)}$ Recently, Datta and $G^{2}{ }^{13}$ ) have indicated that the supplementation of threonine to tyrotoxic rats partially reduces the level of liver Tyr transaminase and pHPP hydroxylase. However, relatively few data are available regarding dietary responses of pHPP hydroxylase and homogentisate oxidase.

On the other hand, several reports have clearly shown that Tyr transaminase fluctuates by the $h r$ of the day, ${ }^{19 \sim 21,23 \sim 29)}$ while the daily variation of pHPP hydroxylase and homogentisate oxidase has not been well demonstrated.

Consequently, the present study was conducted to determine: a) the effect of supplementation of extra casein or methionine plus threonine in rats fed a low protein-high tyrosine diet on liver tyrosine-catabolizing enzyme activities, and $b$ ) the daily variation of these enzymes.

\section{MATERIALS AND METHODS}

Animals and diets. Male weanling rats of the Wistar 
strain were used in these experiments. They were housed individually in suspended cages and kept at $24^{\circ} \mathrm{C}$ in a room with a light period from 05:00 to $17: 00$. Rats were fed a $25 \%$ casein diet for 2 or 3 days and then animals weighing 60 to $65 \mathrm{~g}$ were divided into groups as follows: $10 \%$ casein $(10 \mathrm{C}) ; 10 \mathrm{C}$ containing $5 \% \mathrm{~L}$ tyrosine $(10 \mathrm{C} 5 \mathrm{~T}) ; 10 \mathrm{C} 5 \mathrm{~T}$ supplemented with $0.66 \%$ L-methionine and $0.90 \% \mathrm{~L}-$ threonine (10C5T Met Thr); and $30 \%$ casein containing $5 \%$ L-tyrosine (30C5T). The amounts of supplemented L-methionine and Lthreonine are equivalent to the amino acid content in a $20 \%$ casein.

As described in an earlier report, ${ }^{11)}$ the basal diet (10C) contained: (\%) 10.0 casein; 5.0 salt mixture; 1.0 vitamin mixture; 0.1 choline chloride; 5.0 soybean oil; and $78.9 \alpha$-potato starch. To the other diets, casein or amino acids were added at the expence of an equivalent weight of carbohydrate. Food and water were available ad libitum. Body weight and food intake were recorded daily, but after feeding each experimental diet for 5 days, food consumption was recorded at hourly intervals for $24 \mathrm{hr}$.

Enzyme assays. At the end of 7-day experimental period, rats were killed by decapitation at a different time: $16,19,22,02,05$ and $08: 00 \mathrm{hr}$, respectively. The livers were perfused in situ with ice-cold $0.9 \%$ $\mathrm{NaCl}$ solution, excised, blotted, weighed and homogenized with 2 volumes of ice-cold $0.14 \mathrm{M} \mathrm{KCl}$ solution in a glass homogenizer. The homogenate was filtered through gauze and kept frozen at $-20^{\circ} \mathrm{C}$. The liver homogenate was centrifuged at $10,000 \times g$ for $15 \mathrm{~min}$. The following enzyme activities were measured in the supernatant fraction.

Tyr transaminase (L-tyrosine: 2-oxoglutarate aminotransferase, EC 2.6.1.5) activity was determined by a slight modification of the method of Diamondstone. ${ }^{30)}$ Formed $p$-hydroxyphenylpyruvic acid which was converted to $p$-hydroxybenzaldehyde in strong alkali was measured at $331 \mathrm{~nm}$ using a recording spectrophotometer. The assay mixture contained: $2.4 \mathrm{ml}$ of $0.2 \mathrm{M}$ potassium phosphate buffer, $\mathrm{pH} 7.6$, which was saturated with L-tyrosine; $0.1 \mathrm{ml}$ of $0.3 \mathrm{M} \alpha$-ketoglutarate; $0.1 \mathrm{ml}$ of $1.2 \mathrm{~mm}$ pyridoxal phosphate; $0.2 \mathrm{ml}$ of $0.06 \mathrm{M}$ diethyldithiocarbamate; and $0.2 \mathrm{ml}$ of supernatant fraction.

pHPP hydroxylase ( $p$-hydroxyphenylpyruvate, ascorbate: oxygen oxidoreductase, EC 1.13.11.5) activity was determined using a minor modification of the method of Fellman et al. ${ }^{81)}$ Formed homogentisic acid was condensed with cysteine to yield a 1,4-thiazine with an absorption maximum at $390 \mathrm{~nm}$. The assay mixture contained: $0.7 \mathrm{ml}$ of $0.1 \mathrm{M}$ potassium phosphate buffer, pH $7.3 ; 0.2 \mathrm{ml}$ of $0.01 \mathrm{M} \alpha$ - $\alpha^{\prime}$-dipyridyle; $0.3 \mathrm{ml}$ of $5.7 \mathrm{M}$ L-ascorbic acid; $0.5 \mathrm{ml}$ of $2 \mathrm{~mm} p$-hydroxyphenylpyruvic acid; and $0.3 \mathrm{ml}$ of supernatant fraction.

Homogentisate oxidase (homogentisate: oxygen oxi- doreductase, EC 1.13.11.5) activity was determined according to the method described by Knox et al. ${ }^{32}$ The liver supernatant was treated with $32 \%$ ethyl alcohol and centrifuged. The precipitate was dissolved in water and dialyzed against water for $2 \mathrm{hr}$. The assay mixture contained: $2.0 \mathrm{ml}$ of $0.1 \mathrm{M} \mathrm{2,3,6-collidine} \mathrm{buffer,} \mathrm{pH} 7.2$; $0.7 \mathrm{ml}$ of $0.01 \mathrm{M}$ homogentisic acid; and $0.3 \mathrm{ml}$ of dialyzed solution. The change of the optical density was measured spectrophotometrically at $330 \mathrm{~nm}$ at $27^{\circ} \mathrm{C}$.

Tyrosine determination. Blood was collected into a heparinized centrifuge tube and plasma was prepared by centrifugation. The mixed muscles of the hind legs were cut several times with scissers. A portion of plasma, liver, muscle and brain were homogenized with 2 volumes of $10 \%$ TCA. The protein-free supernatant was used for the determination of free tyrosine with the method of Udenfriend and Cooper. ${ }^{33)}$

\section{RESULTS}

\section{Weight gain and food intake}

As shown in Table I, rats fed the 10C5T diet grew little and had a low level of food intake, which was accompanied by the development of eye lesions. When rats were fed the 30C5T or 10C5T Met Thr diet, weight gain and food intake were appreciably improved and nonpathological lesions were observed. These findings are in agreement with the observation of our previous reports. ${ }^{11,12,14)}$

Table I. Body Weight Gains, Food Intakes and Development of Eye Lesions in Rats Fed THE $10 \%$ CASEIN (10C) AND THE 10C Plus $5 \%$

TYRosine (10C5T) DIETS WITH AND WITHOUT Extra Casein or Methionine Plus Threonine

\begin{tabular}{lccc}
\hline Groups & $\begin{array}{c}\text { Body weight } \\
\text { gain } \\
\text { (g/7 days) }\end{array}$ & $\begin{array}{c}\text { Food } \\
\text { intake } \\
(\mathrm{g} / 7 \text { days })\end{array}$ & $\begin{array}{c}\text { Development } \\
\text { of eye } \\
\text { lesions }\end{array}$ \\
\hline $10 \mathrm{C}$ & $14.2 \pm 0.6^{1) a}$ & $59.3 \pm 0.8^{a}$ & $0 / 18$ \\
$10 \mathrm{C} 5 \mathrm{~T}$ & $2.6 \pm 0.5^{b}$ & $44.4 \pm 0.7^{b}$ & $18 / 18$ \\
10C5T & & & \\
Met Thr & $25.4 \pm 0.7^{\circ}$ & $52.3 \pm 0.7^{\circ}$ & $0 / 18$ \\
$30 \mathrm{C} 5 \mathrm{~T}$ & $35.5 \pm 1.0^{d}$ & $61.0 \pm 0.9^{a}$ & $0 / 18$ \\
\hline
\end{tabular}

1) Mean $\pm \mathrm{SE}$ of 18 rats. Values with different superscript are significantly different at $p<0.05$.

The variation in food intake hourly for $24 \mathrm{hr}$ and the cumulative amount of food intake for each $12 \mathrm{hr}$ during dark and light periods after the 5-day feeding are shown in Fig. 1 and Table II, respectively. As some previous re- 


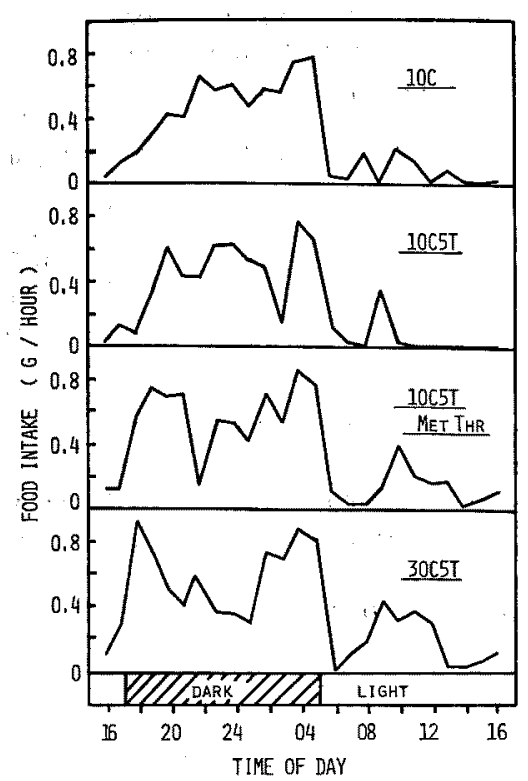

FIG. 1. Daily Variation in Hourly Food Intake during Dark and Light Periods.

Rats were fed the 10C and the 10C5T diets with and without extra casein or methionine plus threonine ad libitum for 5 days in a room with a light period from 05:00 to 17:00, then the food intake was recorded hourly over 24-hr period. Each point represents the mean of 5 rats.

TABle II. Average Food INTAKe during Dark AND Light Periods

Data show the cumulative amounts of food intake for each $12 \mathrm{hr}$ during dark and light periods after the 5-day feeding. The values were calculated from the data of Fig. 1.

\begin{tabular}{|c|c|c|c|}
\hline Groups & $\begin{array}{r}\text { Dark period } \\
(17: 00-05: 00)\end{array}$ & $\begin{array}{l}\text { Light period } \\
(05: 00-17: 00)\end{array}$ & Total \\
\hline & $\mathrm{g} / 12 \mathrm{hr}$ & $\mathrm{g} / 12 \mathrm{hr}$ & $\mathrm{g} / 24 \mathrm{hr}$ \\
\hline $10 \mathrm{C}$ & $7.1 \pm 0.2^{1) a}$ & $1.2 \pm 0.3^{a . b}$ & $8.3 \pm 0.3^{a}$ \\
\hline $\begin{array}{l}10 \mathrm{C} 5 \mathrm{~T} \\
10 \mathrm{C} 5 \mathrm{~T}\end{array}$ & $6.1 \pm 0.3^{b}$ & $0.9 \pm 0.3^{\alpha}$ & $7.0 \pm 0.3^{b}$ \\
\hline Met Thr & $7.4 \pm 0.3^{a}$ & $1.9 \pm 0.3^{b}$ & $9.3 \pm 0.2^{a}$ \\
\hline $30 \mathrm{C} 5 \mathrm{~T}$ & $7.3 \pm 0.3^{a}$ & $2.3 \pm 0.4^{b}$ & $9.6 \pm 0.3^{a}$ \\
\hline
\end{tabular}

i) Mean $\pm S E$ of 5 rats. Values with different superscript are significantly different at $p<0.05$.

ports have indicated, ${ }^{27,34)}$ rats in all groups ingested a large amount of food during darkness, and ate a very little food during lightness. Rats consuming the 10C5T diet had the lowest level of food intake during both dark and light periods, whereas the food consumption of rats receiving the $30 \mathrm{C} 5 \mathrm{~T}$ or the $10 \mathrm{C} 5 \mathrm{~T}$ Met $\mathrm{Thr}$ diet was increased during both periods.

\section{Liver enzyme activities}

Mean value of activities of Tyr transaminase, pHPP hydroxylase and homogentisate oxidase at 16,19,22,02, 05 and 08:00 during 24-hr period is shown in Table III. Tyr transaminase activity in rats fed the 10C5T diet increased more than control (10C) and coursed further increase in rats fed the $30 \mathrm{C} 5 \mathrm{~T}$ diet. In contrast, the supplementation of methionine and threonine to the 10C5T diet had no effect on an increase of this enzyme. pHPP hydroxylase activity was depressed significantly in rats fed the 10C5T diet, but this enzyme was elevated 2 or 3 fold by dietary addition of casein or methionine and threonine. Homogentisate oxidase activity resulted in some depression in rats fed the 10C5T diet, and the addition of casein or methionine plus threonine to the diet had no effect on an elevation of this enzyme.

The ratio of activities of Tyr transaminase to pHPP hydroxylase was markedly high in rats consuming the 10C5T diet and lowered to about control level by the addition of casein or methionine plus threonine. The ratio of these two enzymes seems to be correlated to tyrosine toxicity.

The daily variations in liver Tyr trans-

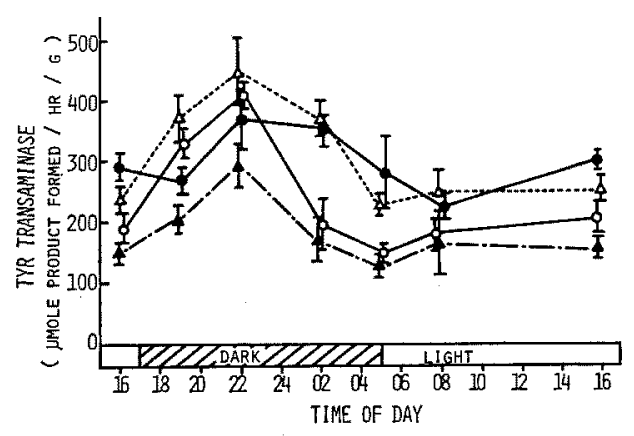

FIG. 2. Daily Variation in Liver Tyr Transaminase Activity in Rats Fed the 10C and the 10C5T Diets with and without Extra Casein or Methionine Plus Threonine ad libitum.

Lights were on from 05:00 to 17:00 daily. Each point represents the mean of 3 rats and the vertical line indicates SE. $\bigcirc-0,10 \mathrm{C} ; \bullet-\bullet, 10 \mathrm{C} 5 \mathrm{~T} ; \triangle-\cdots$, 10C5T Met Thr; $\triangle--\triangle$, 30C5T. 
Table III. Mean Activities of Liver Tyr Transaminase, PHPP Hydroxylase and Homogentisate Oxidase in Rats Fed the 10C and the 10C5T Diets with and without Extra Casein or Methionine plus Threonine

\begin{tabular}{lcccc}
\hline Groups & $\begin{array}{c}\text { Tyr } \\
\text { transaminase }^{1)}\end{array}$ & $\begin{array}{c}\text { pHPP } \\
\text { hydroxylase }\end{array}$ & $\begin{array}{c}\text { Homogentisate } \\
\text { oxidase }^{3)}\end{array}$ & \begin{tabular}{c} 
Tyr transaminase \\
\cline { 5 - 5 }
\end{tabular} \\
\hline 10C & $217 \pm 36^{4) a b}$ & $39.9 \pm 2.1^{a}$ & $13.0 \pm 1.1^{a}$ & $5.67 \pm 0.36^{a}$ \\
10C5T & $294 \pm 20^{a}$ & $21.0 \pm 1.2^{b}$ & $9.8 \pm 0.9^{b}$ & $13.87 \pm 1.43^{b}$ \\
10C5T Met Thr & $181 \pm 14^{b}$ & $49.5 \pm 2.3^{a}$ & $11.4 \pm 1.0^{a b}$ & $3.58 \pm 0.20^{a}$ \\
30C5T & $318 \pm 26^{a}$ & $62.0 \pm 2.2^{d}$ & $8.9 \pm 0.8^{b}$ & $5.07 \pm 0.33^{a}$ \\
\hline
\end{tabular}

1) Tyr transaminase activity was expressed as $\mu$ moles of $p$-hydroxyphenylpyruvic acid formed $/ \mathrm{hr} / \mathrm{g}$ liver.

2) pHPP hydroxylase activity was expressed as $\mu$ moles of homogentisic acid formed/hr/g liver.

a) Homogentisate oxidase activity was expressed as $\mu$ moles of maleylacetoacetic acid formed $/ \mathrm{hr} / \mathrm{g}$ liver.

4) Each value represents mean \pm SE of the activity at 16, 19, 22, 02, 05 and 08:00 during 24-hr period indicated in Figs. 2, 3, or 4.

Values with different superscript are not significantly different at $p<0.05$.

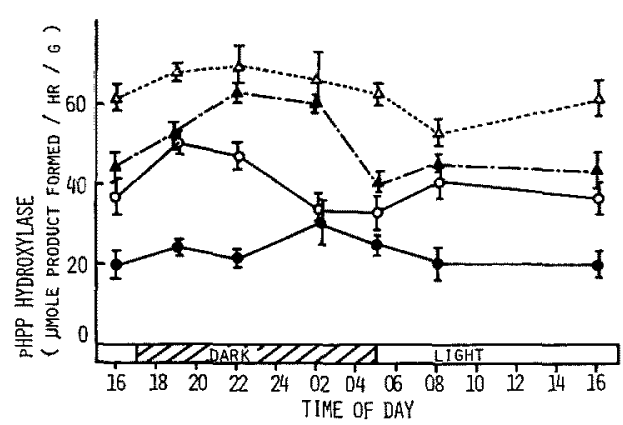

FIG. 3. Daily Variation in Liver pHPP Hydroxylase Activity in Rats Fed the 10C and the 10C5T Diets with and without Extra Casein or Methionine Plus Threonine ad libitum.

Lights were on from 05:00 to 17:00 daily. Each point represents the mean of 3 rats and the vertical line indicates SE. $\mathrm{O}-\mathrm{O}, 10 \mathrm{C} ; \bullet-\bullet, 10 \mathrm{C} 5 \mathrm{~T} ; \mathbf{\Lambda - - \Lambda}$, 10C5T Met Thr; $\triangle-\cdots \Delta, 30 \mathrm{C} 5 \mathrm{~T}$.

aminase, pHPP hydroxylase and homogentisate oxidase are shown in Figs. 2, 3 and 4, respectively. In accord with other observations, ${ }^{19 \sim 21,23 \sim 29)}$ Tyr transaminase clearly exhibited a daily rhythm with the activity pattern of the enzyme similar in all dietary groups except the 10C5T. The peak of the activity of their groups showed about $5 \mathrm{hr}$ after the onset of the darkness, while the peak value in rats fed the 10C5T diet was between 5 and $9 \mathrm{hr}$ after the beginning of the darkness. Furthermore, the activity pattern in rats receiving the 10C5T Met Thr was lower than those of other groups throughout the 24-hr period.

pHPP hydroxylase in all groups did not show

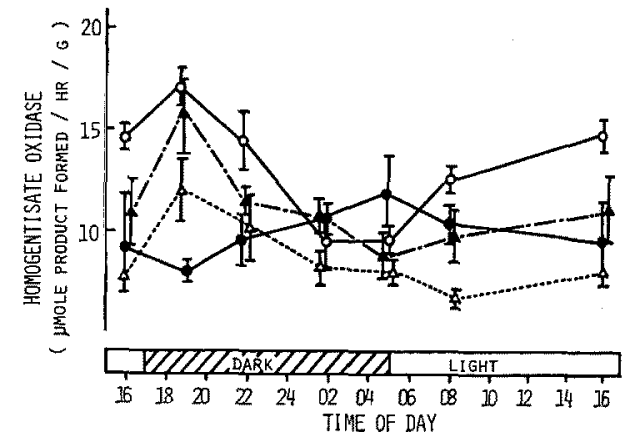

FIG. 4. Daily Variation in Liver Homogentisate Oxidase Activity in Rats Fed the 10C and the 10C5T Diets with and without Extra Casein or Methionine Plus Threonine ad libitum.

Lights were on from 05:00 to 17:00 daily. Each point represents the mean of 3 rats and the vertical

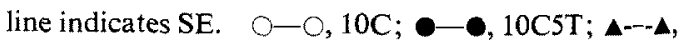
10C5T Met Thr; $\triangle--\triangle$, 30C5T.

clear-cut diurnal variation as Tyr transaminase, although somewhat rises of the activity occurred during the dark period. However, there was significant difference in the level of the pattern among their groups. The pattern in rats fed the 30C5T diet had the highest level over the dark and light periods, and was followed in decreasing order by the $10 \mathrm{C} 5 \mathrm{~T}$ Met Thr, 10C and 10C5T groups.

Homogentisate oxidase showed a diurnal variation, but the rhythm was not clear-cut as seen in Tyr transaminase. The peak of this enzyme activity occurred about $2 \mathrm{hr}$ after the onset of the darkness in all groups, except the 10C5T in which it shifted to the end of the 
Table IV. Free Tyrosine Concentrations in Plasma and Tissues of Rats Fed the 10C and the 10C5T Diets with and without Extra Casein or Methionine plus Threonine

\begin{tabular}{|c|c|c|c|c|}
\hline \multirow{2}{*}{ Groups } & \multirow{2}{*}{$\begin{array}{c}\text { Plasma } \\
(\mathrm{mg} / 100 \mathrm{ml})\end{array}$} & Liver & Muscle & Brain \\
\hline & & \multicolumn{3}{|c|}{ ( $\mu \mathrm{g} / \mathrm{g}$ tissue $)$} \\
\hline $10 \mathrm{C}$ & $2.2 \pm 0.1^{1) a}$ & $93.7 \pm 4.8^{a}$ & $29.4 \pm 1.1^{a}$ & $25.7 \pm 1.5^{a}$ \\
\hline $10 \mathrm{C} 5 \mathrm{~T}$ & $63.3 \pm 2.4^{6}$ & $673.8 \pm 2.3^{b}$ & $1088.0 \pm 55.0^{b}$ & $488.3 \pm 13.0^{b}$ \\
\hline 10C5T Met Thr & $12.8 \pm 0.9^{c}$ & $190.0 \pm 5.0^{\circ}$ & $136.8 \pm 6.5^{\circ}$ & $116.1 \pm 7.1^{\circ}$ \\
\hline $30 \mathrm{C} 5 \mathrm{~T}$ & $9.7 \pm 0.7^{d}$ & $180.2 \pm 9.0^{\circ}$ & $138.9 \pm 13.6^{\circ}$ & $91.1 \pm 12.8^{\circ}$ \\
\hline
\end{tabular}

dark period.

\section{Free tyrosine concentration in tissues}

As shown in Table IV, free tyrosine concentrations in plasma and tissues elevated extremely in the 10C5T groups but the marked reduction of free tyrosine was observed when extra casein or methionine plus threonine was added to the high tyrosine diet.

\section{DISCUSSION}

It is well known that liver Tyr transaminase responds to the substrate, tyrosine, ${ }^{4,5,12,13,15,10)}$ and can be induced by dietary protein..$^{4,5,17 \sim 21,}$ In the present report, we could confirm the fact, but the addition of methionine and threonine to a high tyrosine diet caused rather a lowering of this enzyme level. In this regard, Datta and $\mathrm{Ghosh}^{13)}$ have showed that the supplement of threonine to a high tyrosine diet partially reduced the level of Tyr transaminase.

In consistent with the earlier reports, ${ }^{4,5}$, pHPP hydroxylase activity was depressed by feeding a low protein-high tyrosine diet and elevated markedly by dietary addition of casein. In addition, the present results also showed that this enzyme activity was increased by the supplement of methionine and threonine to the high tyrosine diet.

It has been reported that homogentisate oxidase activity failed to increase in rats which were fed a diet containing adequate amounts of protein, ${ }^{4,5)}$ while it was increased by feeding a high protein diet with or without excess tyrosine. ${ }^{5}$
From these results of in vitro enzyme studies, it seems probable that pHPP hydroxylase is the limiting enzyme in this experimental conditions, and that there is a close relationship between the elevation of pHPP hydroxylase and the capacity to overcome the tyrosine toxicity. Moreover, the ratio of Tyr transaminase and pHPP hydroxylase would appear to reflect the severity of tyrosine toxicity. When rats were fed a low protein-high tyrosine diet, Tyr transaminase was elevated and pHPP hydroxylase was lowered, then the ratio of the two enzymes elevated markedly. Similarly, Knox et $a l^{35)}$ and Datta and Ghosh ${ }^{13)}$ have reported the importance of the ratio of the two enzyme activities to understand tyrosyluria or tyrosine toxicity.

The daily variation in liver Tyr transaminase activity has been well documented, ${ }^{19 \sim 21,23 \sim 29}$ ) but that of pHPP hydroxylase and homogentisate oxidase is poorly understood. The results of the present experiment indicated that the activities of Tyr transaminase of all experimental groups studied attained a peak within darkness, and that rats ate almost their daily diets during the dark period. The daily rhythm of this enzyme appears to have close relationship with the daily rhythm of food intake. In contrast, pHPP hydroxylase and homogentisate oxidase did not show so much clear diurnal variation.

Results of the oxidation study which was carried out under the similar experimental conditions $^{14)}$ showed that the dietary addition of extra casein or methionine and threonine to a low protein-high tyrosine diet enhanced 
significantly the ability of tyrosine oxidation to $\mathrm{CO}_{2}$. Furthermore, their patterns of tyrosine oxidation were clearly correlated with the activity patterns of pHPP hydroxylase among the liver tyrosine-catabolizing enzymes.

From the present results and the previous findings, ${ }^{14)}$ it is suggested that the supplement of casein or methionine and threonine to a high tyrosine-low protein diet improves the nutritional quality, and increases the capacity of tyrosine metabolism by increasing liver pHPP hydroxylase which would be the first limiting enzyme in tyrosine catabolic system, thus the removal of excessive amount of tyrosine in the body being facilitated.

\section{REFERENCES}

1) H. E. Sauberlich, J. Nutr., 75, 61 (1961).

2) A. E. Harper, R. V. Becker and W.P. Stucki, Proc. Soc. Exp. Biol. Med., 121, 695 (1966).

3) K. Muramatsu, H. Odagiri, S. Morishita and $H$. Takeuchi, J. Nutr., 101, 1117 (1971).

4) C. C. Y.Ip and A. E. Harper, ibid., 103, 1594 (1973).

5) K. Muramatsu, M. Takei and K. Nakamura, ibid., 105, 439 (1975).

6) D. A. Benton, A. E. Harper, H. E. Spivey and C. A. Elvehjem, Arch. Biochem. Biophys., 60, 156 (1956).

7) S. Q. Alam, R. V. Becker, W. P. Stucki, Q. R. Rogers and A. E. Harper, J. Nutr., 89, 91 (1966).

8) S. Q. Alam, Q. R. Rogers and A. E. Harper, ibid., 89, 97 (1966).

9) C. Godin, ibid., 92, 503 (1967).

10) S. Q. Alam, A. M. Boctor, Q. R. Rogers and A. E. Harper, ibid., 93, 317 (1967).

11) K, Muramatsu, T. Arito and H. Tsuda, J. Nutr. Sci. Vitaminol., 22, 397 (1976).

12) Y. Yamamoto, H. Katayama and K. Muramatsu, ibid., 22, 467 (1976).
13) K. Datta and J. J. Ghosh, J. Nutr., 107, 1575 (1977).

14) K. Muramatsu, Y. Yamamoto and R. Toyoshima, Rep. Res. Comm. Essen, Amino Acids, 76, 9 (1977).

15) E. C. C. Lin and W. E. Knox, Biochim. Biophys. Acta, 26, 85 (1957).

16) W. E. Knox, Adv. Enzyme Regul., 2, 311 (1964).

17) Z. H. Al-Nejjar and G. Litwack, Biochim. Biophys. Acta, 48, 153 (1961).

18) F. Rosen, H. R. Harding, R. J. Milholland and C. A. Nichol, J. Biol. Chem., 238, 3725 (1963).

19) B. Szepesi and R. A. Freedland, J. Nutr., 93, 301 (1967).

20) R. A. Freedland, Can. J. Biochem., 46, 1253 (1968).

21) R. D. Reynolds, V. R. Potter and H. C. Pitot, $J$. Nutr., 101, 797 (1971).

22) V. Csányi, O. Greengard and W. E. Knox, J. Biol. Chem., 242, 2688 (1967).

23) A. Girard-Globa and G. Bourdel, J. Nutr., 103, 251 (1973).

24) R. J. Wurtman and J. Axelrod, Proc. Natl. Acad. Sci. U.S.A., 57, 1594 (1967).

25) M. Civen, R. Ulrich, B. M. Trimmer and C. R. Brown, Science, 157, 1563 (1967).

26) G. E. Shambaugh, III, D. A. Warner and W. R. Beisel, Endocrinology, 81, 811 (1967).

27) M. J. Zigmond, W. J. Shoemaker, F. Larin and R. J. Wurtman, J. Nutr, 98, 71 (1969).

28) C. Cohn, D. Joseph, F. Larin, W. J. Shoemaker and R. J. Wurtman, Proc. Soc. Exp. Biol. Med., 133, 460 (1970).

29) R. W. Fuller, ibid., 133, 620 (1970).

30) T. I. Diamondstone, Anal. Biochem., 16, 395 (1966).

31) J. H. Fellman, T. S. Fujita and E. S. Roth, Biochim. Biophys. Acta, 284, 90 (1972).

32) W. E. Knox and S. W. Edwards, J. Biol. Chem., 216, 479 (1955).

33) S. Udenfriend and J. R. Cooper, ibid., 196, 227 (1952).

34) P. S. Siegel and H. L. Stackey, J. Comp. Physiol. Psychol., 40, 365 (1947).

35) W. E. Knox, M. C. Linder, R. D. Lynch and C. L. Moore, I. Biol. Chem., 239, 3821 (1964). 